\title{
Correlation between Patient's Age and Advanced Response Time with Outcome of Cardio Pulmonary Resuscitation in Cardiac Arrest Patient
}

\author{
Debie Setiarini ${ }^{1}$, Prihatma Kriswidyatomo², Gadis Meinar Sari
}

\author{
${ }^{1}$ Faculty of Medicine, Universitas Airlangga, Surabaya, Indonesia. \\ 2 Department of Anaesthesiology and Reanimation, Faculty of Medicine, Universitas Airlangga - Dr. Soetomo General Hospital, \\ Surabaya, Indonesia. \\ ${ }^{3}$ Department of Medical Physiology, Faculty of Medicine, Universitas Airlangga, Surabaya, Indonesia.
}

\section{A B S T R A C T}

Introduction: This study is conducted to determine the correlation between patient's age and advanced response time with the outcome of Cardio Pulmonary Resuscitation in cardiac arrest patients.

Methods: This was an analytic observational cross-sectional study, evaluating correlation between patient's age and advanced response time with the outcome of Cardio Pulmonary Resuscitation in cardiac arrest patients. This study used the primary data from Cardio Pulmonary Resuscitation sheets from February to August 2018 at Dr. Soetomo General Hospital, Surabaya. The data were analysed with Chi Square and Contingency Coefficient using SPSS version 22.0.

Results: The results showed that $84.6 \%$ cardiac arrest patients who experience ROSC are over 40 years old, and $92.3 \%$ cardiac arrest patients who experience ROSC have advanced response time $\leq 5$ minutes. After being tested using Chi Square, patient's age was not statistically influencing the outcome in cardiac arrest patients $(p=0.507)$, but advanced response time was statistically influencing the outcome in cardiac arrest patients $(p=0.001)$.

Conclusion: There was no statistically influence of patient's age towards the outcome in cardiac arrest patients, but there was a significant influence of advance response time towards the outcome in cardiac arrest patients.

\footnotetext{
* Correspondence: prihatma@gmail.com

JUXTA: Jurnal IImiah Mahasiswa Kedokteran Universitas Airlangga p-ISSN: 1907-3623; e-ISSN: 2684-9453

DOI: $10.20473 /$ juxta.V10I22019.67-69
}

Open access under Creative Commons Attribution-ShareAlike 4.0 International License (CC-BY-SA)

\section{ARTICLE INFO}

Article history:

Received 07 August 2019

Received in revised form 15

August 2019

Accepted 22 August 2019

\section{Keywords:}

Cardiac Arrest,

Advanced Response Time,

Patient's Age,

Outcome. 


\section{Introduction}

Cardiac Arrest is a sudden loss of heart function that causes the disruption of blood circulation to the brain, lungs and other organs. The timing of cardiac arrest is unpredictable. It can happen to anyone, anywhere, and anytime. Therefore, proper treatment is needed to improve the Return of Spontaneous Circulation (ROSC) outcome and survival rates in cardiac arrest patients. One of the appropriate treatments for cardiac arrest patient is Cardio Pulmonary Resuscitation (CPR). The good quality of CPR must be done, in order to provide good outcome for the patients. Despite of the good quality of CPR, there are many other factors that might influence the outcome in cardiac arrest patients. These factors include the patient's gender, age, advanced response time by Code Blue team, duration of CPR, and also the patient's base disease, but these factors have not been studied certainly. ${ }^{1}$

The incidence of cardiac arrest that occurs in hospitals in Indonesia is 10 cases out of 100,000 people aged less than 35 years and annually reaching 300,000-350,000 cardiac arrest events. ${ }^{2}$ According to a study by Madl and Holzer (2010), only $17-49 \%$ of cardiac arrest patients will experience ROSC after being helped by CPR. ${ }^{3,4}$

According to the American Heart Association (2015), $\mathrm{CPR}$ is the main guideline on treating patients with cardiac arrest, but the percentage of ROSC outcome in cardiac arrest patients after being helped by CPR is still quite low at less than $50 \% .{ }^{5}$ The low percentage of ROSC outcome can be influenced by many other factors, but the influence of these factors has not been studied certainly. ${ }^{6}$

The incidence of cardiac arrest is very high, but the ROSC outcome in cardiac arrest patients who are helped by CPR is still not really good, even though CPR is the main guideline on treating cardiac arrest patients. This fact leads the researchers to find out whether some factors like patient's age and advanced response time by Code Blue team can influence the outcomes in cardiac arrest patients. These factors were chosen by the researchers because it is seldom to find out about the correlation in other researches. ${ }^{7}$

It is expected that after the factors influencing outcome in cardiac arrest patients are known, the treatment of cardiac arrest patients will be more optimal, and it can improve the ROSC outcome or survival rate in cardiac arrest patients.

\section{Methods}

This was an analytic observational study using crosssectional design. This study was conducted at the Department of Anaesthesiology and Reanimation, Dr. Soetomo General Hospital, from February to August, 2018. The population of this study was all the cardiac arrest patients at Dr. Soetomo General Hospital. This study used total sampling technique. The inclusion criteria of the samples were patients who had completed CPR Sheet. The exclusion criteria of the samples were patients who had not completed CPR Sheet. This study used primary data from CPR Sheet from cardiac arrest patients. The total samples of this study from 8 months are 76 patients.

Data were analysed with descriptive statistics and presented in frequency distribution tables. Data were also analysed with Chi Square and Contingency Coefficient using SPSS version 22.0. It was analysed with Chi Square to determine whether the factors influence the outcome in cardiac arrest patients or not. It was analysed with Contingency Coefficient to determine the value of the influence between the factors and the outcome.

\section{Results}

The total number of samples in this study was 76 cardiac arrest patients who met the inclusion and exclusion criteria. The number of patients who experienced ROSC was 13 patients, which is $17.1 \%$ of the total samples, and the other 63 patients did not experience ROSC, which is $82.9 \%$ of the total samples.

Table 1. General characteristics of the patients.

\begin{tabular}{lcc}
\hline \multicolumn{1}{c}{ Characteristics } & ROSC & Non ROSC \\
Age (years) & & \\
$\leq 40$ years old & $15(23.8 \%)$ & $15(23.8 \%)$ \\
$>40$ years old & $2(15.4 \%)$ & $48(76.2 \%)$ \\
Advanced Response Time & & \\
$\leq 5$ minutes & $11(84.6 \%)$ & $26(41.3 \%)$ \\
$>5$ minutes & $12(92.3 \%)$ & $37(58.7 \%)$ \\
\hline
\end{tabular}

Patients who experienced cardiac arrest were mostly over 40 years old. The patients over 40 years old were about 3.5 times more than patients who are less than or equal to 40 years old. It is also known that $50 \%$ of the cardiac arrest patients were helped by code blue team with advance response time less than or equal to 5 minutes, and the other $50 \%$ were helped by code blue team with advance response time more than 5 minutes.

It is known that $84.6 \%$ of cardiac arrest patients who experienced ROSC were over 40 years old. It is also known that $92.3 \%$ cardiac arrest patients who experienced ROSC have advanced response time less than or equal to 5 minutes. Otherwise, $58.7 \%$ cardiac arrest patients who experienced non ROSC have advanced response time more than 5 minutes. From these results, it is known that patients with ROSC outcomes tend to have short advanced response times ( $\leq 5$ minutes), whereas patients with outcomes not ROSC tend to have longer advanced response time ( $>5$ minutes).

\section{The Correlation between Factors and Outcome of Cardiac Arrest Patients}

The factors such as patient's age and advanced response time by Code Blue team were analysed with Chi Square to determine whether the factors are influencing the outcomes or not. 
Table 2. Correlation between Factors and Outcome of Cardiac Arrest Patients.

\begin{tabular}{lc}
\hline \multicolumn{1}{c}{ Factors } & Sig $(p)$ \\
\hline Age & 0.507 \\
Advance Responces Time & 0.001 \\
\hline
\end{tabular}

From the results, it is known that patient's age is not influencing the outcome on cardiac arrest patients $(p \geq$ $0.05)$. Otherwise, advanced response time is influencing the outcome on cardiac arrest patients $(p<0.05)$.

\section{The Value of the Influence between Factors and Outcome of Cardiac Arrest Patients}

The factor that is influencing the outcome on cardiac arrest patients $(p<0,05)$, such as advanced response time by Code Blue team was analysed with Contingency Coefficient to determine the value of the influence between that factor towards the outcome in cardiac arrest patients.

Table 3. The Value of the Influence between Factor and Outcome of Cardiac Arrest Patients.

\begin{tabular}{cc}
\hline Factors & $\begin{array}{c}\text { Contingency } \\
\text { Coefficient }(\mathrm{C})\end{array}$ \\
\hline Advance Responces Time & 0.359 \\
\hline
\end{tabular}

From the results, it is known that the value of the influence between advanced response time towards the outcome in cardiac arrest patients is 0.359 . It shows that the factor is significantly influencing the outcome in cardiac arrest patients. It is based on the classification made by Blaikie (2003). ${ }^{8}$

\section{Discussion}

This research was conducted to determine the factors influencing ROSC outcome after CPR in cardiac arrest patients. Some factors were analysed in this study such as patient's age and advanced response time by Code Blue team.

The results showed that cardiac arrest patients over 40 years old are $77,6 \%$, which is 3.5 times more than the patients who are less than or equal to 40 years old $(22,4 \%)$. It is similar with the study conducted in Brazil which showed that $70.5 \%$ of cardiac arrest patients are over 40 years old and $29,5 \%$ of cardiac arrest patients are less than or equal to 40 years old. ${ }^{9}, 10$ This can occur because by increasing the patient's age, the risk of experiencing comorbid diseases or terminal diseases is also getting bigger. ${ }^{1,11}$

Statistically, the patient's age did not show a significant difference towards outcome in cardiac arrest patients. This is in line with the previous studies which said that age is not one of the factors or variables which determine the outcomes in cardiac arrest patients. ${ }^{12,13}$

From the results, it is known that patients with ROSC outcomes tend to have short advanced response times ( $\leq$ 5 minutes), whereas patients with outcomes not ROSC tend to have longer advanced response time (> 5 minutes). It is similar with the previous study which said that $83.3 \%$ cardiac arrest patients who experienced ROSC had advanced response time $<4$ minutes. ${ }^{11,12}$

Statistically, the advanced response time shows a significant difference towards outcome in cardiac arrest patients. This is in line with the previous study which said that patient who has advanced response time $\leq 5$ minutes had an outcome 2.53 times better than patient who had advanced response time $>5$ minutes. $^{9,14}$ In this study, the value of the difference statistically between response time towards the outcome in cardiac arrest patients is $35.9 \%$, which means significantly difference according to Blaikie classification (2003). ${ }^{8}$

It means that the longer of the advanced response time in cardiac arrest patients, the outcome of non ROSC or death in patients will increase as well. The significant influence between advanced response time and the outcome of cardiac arrest patients can be caused by many things. One of them is because the oxygen that left in the lungs and blood only supplies the oxygen need of the body in about 5 minutes. If there is no supply of oxygen after 5 minutes, then the body's cells will slowly experience permanent death, especially the organs that need the most oxygen and easily experience ischemic injury, such as brain. Therefore, the golden time to start CPR in order to provide a good outcome in cardiac arrest patients is $\leq 5$ minutes. ${ }^{13,15}$

The results showed that only $17.1 \%$ of cardiac arrest patients experienced ROSC after being helped by CPR. The other $82.9 \%$ of patients did not experience ROSC after being helped by CPR. It is similar with the previous study who said that only $23-25 \%$ of cardiac arrest patients experienced ROSC after being helped by CPR. ${ }^{1,9}$

\section{Conclusion}

ROSC outcome is still difficult to be reached in cardiac arrest patients. Therefore, this study was conducted to determine whether the patient's age and advanced response time by Code Blue team can influence the outcome in cardiac arrest patients. From the overall results of this study, it was found that the patient's age did not influence the outcomes in cardiac arrest patients. Otherwise the advanced response time by code blue team significantly influenced the outcomes in cardiac arrest patients. From these results, it can be said that the efforts to shorten the advanced response time are expected to improve ROSC outcomes in cardiac arrest patients. By knowing these factors, it is expected that the ROSC outcome in cardiac arrest patients can be further improved. Helper factors such as advanced response time can be optimized to improve ROSC outcomes in cardiac arrest patients.

Beside the factors that were analysed in this study, there were other factors that also predicted to influence the outcomes in cardiac arrest patients, so further study is needed to analyse the other factors that might influence the outcome in cardiac arrest patients. 


\section{CONFLICT OF INTEREST}

The author stated there is no conflict of interest in this study.

\section{REFERENCES}

1.Xue J-K, Leng Q-Y, Gao Y-Z, et al. Factors influencing outcomes after cardiopulmonary resuscitation in emergency department. World J Emerg Med. 2013; 4: 183-9.

2.Indonesia PDSK. Henti Jantung. Perhimpunan Dokter Spesialis Kardiovaskular Indonesia, 2015.

3.Perkins GD, Handley AJ, Koster RW, et al. European Resuscitation Council Guidelines for Resuscitation 2015: Section 2. Adult basic life support and automated external defibrillation. Resuscitation. 2015; 95: 81-99.

4.Madl $\mathrm{C}$ and Holzer M. Brain function after resuscitation from cardiac arrest. Current opinion in critical care. 2004; 10: $213-7$

5.Association AH. 2015 American Heart Association Guidelines Update for Cardiopulmonary Resuscitation and Emergency Cardiovascular Care. Circulation. 2015; 132.

6. Taufik M. Tingkat Keberhasilan Awal Cardiopulmonary Resusitasi dan Faktor yang Berhubungan dengan Tingkat Keberhasilannya Antara Pasien yang Dirawat di Unit Perawatan Intensif (ICU) di Rumah Sakit Kelas Ketiga di Arab Saudi. Makassar: Universitas Hasanuddin, 2017.

7.Yannopoulos D, Aufderheide TP, Abella BS, et al. Quality of CPR: An important effect modifier in cardiac arrest clinical outcomes and intervention effectiveness trials. Resuscitation. 2015; 94: 106-13.

8.Blaikie N. Analyzing Quantitative Data: From Description to Explanation. 1st ed. London: SAGE Publications, 2003.

9.Gomes AMdCG, Timerman A, Souza CAMd, et al. Fatores prognósticos de sobrevida pós-reanimação cardiorrespiratória cerebral em hospital geral. Arquivos Brasileiros de Cardiologia. 2005; 85: 262-71.

10.Syue Y-J, Huang J-B, Cheng F-J, Kung C-T and Li C-J. The Prognosis of Cardiac Origin and Noncardiac Origin inHospital Cardiac Arrest Occurring during Night Shifts. BioMed Research International. 2016; 2016: 7.

11.Moosajee US, Saleem SG, Iftikhar S and Samad L. Outcomes following cardiopulmonary resuscitation in an emergency department of a low- and middle-income country. International Journal of Emergency Medicine. 2018; $11: 40$.

12.Tok D, Keles GT, Toprak V and Topcu I. Assessment of in-hospital cardiopulmonary resuscitation using Utstein template in a university hospital. The Tohoku journal of experimental medicine. 2004; 202: 265-73.

13.Oh TK, Park YM, Do S-H, Hwang J-W and Song I-A. ROSC rates and live discharge rates after cardiopulmonary resuscitation by different CPR teams - a retrospective cohort study. BMC Anesthesiol. 2017; 17: 166 -

14.Burger A, Wnent J, Bohn A, et al. The Effect of Ambulance Response Time on Survival Following Out-ofHospital Cardiac Arrest. Deutsches Arzteblatt international. 2018; 115: 541-8.

15. Hajbaghery MA, Mousavi G and Akbari H. Factors influencing survival after in-hospital cardiopulmonary resuscitation. Resuscitation. 2005; 66: 317-21. 